indicates that autosomal recessive inheritance is probable.

\footnotetext{
References

${ }^{1}$ Fryns JP, Moerman F, Goddeeris P, Bossuyt C, Van den Berghe H. A new lethal syndrome with cloudy corneae, diaphragmatic defects and distal limb deformities. Hum Gener 1979;50:65-70.

${ }^{2}$ Goddeeris P, Fryns JP, Van den Berghe H. Diaphragmatic defects, craniofacial dysmorphism, cleft palate and distal limb deformities - a new lethal syndrome. J Genet Hum 1980;28: 57-60.

${ }^{3}$ Lubinsky M, Severn C, Rapoport JM. Fryns syndrome: a new variable multiple congenital anomaly (MCA) syndrome. Am J Med Genet 1983;14:461-6.
}

${ }^{4}$ Opitz JM, Zu Rhein GM, Vitale L, et al. The Zellweger syndrome (cerebro-hepato-renal syndrome). Birth Defects $1969 ; \mathrm{V}(2): 144-60$.

5 Danks DM, Tippett P, Adams C, Campbell P. Cerebro-hepatorenal syndrome of Zellweger: a report of eight cases with comments upon the incidence, the liver lesion, and a fault in pipecolic acid metabolism. J Pediatr 1975;86:382-7.

6 Trijbels JMF, Berden JA, Monnens LAH, et al. Biochemical studies in the liver and muscle of patients with Zellweger syndrome. Pediatr Res 1983;17:514-7.

Correspondence and requests for reprints to Dr I D Young, Department of Child Health, Clinical Sciences Building, PO Box 65, Leicester Royal Infirmary, Leicester LE2 7LX.

\title{
Umbilical cord hernia in a child with autosomal recessive chondrodysplasia punctata
}

\author{
O CHANDAVASU AND F DESPOSITO
}

Neonatal Services, Jersey City Medical Center; and Departments of Pediatrics and Human Genetics, University of Medicine and Dentistry of New Jersey, Jersey City, New Jersey, USA.

SUMMARY An infant with congenital chondrodysplasia punctata with a secondary deformation of umbilical cord hernia is reported. The paper discusses deformation syndromes as anomalies due to unusual mechanical or intrinsic factors.

Deformations resulting from in utero compression are relatively common problems, first described by Hippocrates. ${ }^{1}$ Little attention had been paid to their pathophysiology until $\mathrm{Smith}^{2}$ reported several varieties of deformation and deformation sequences due to extrinsic mechanical forces causing in utero fetal constraint, especially during the rapid growth period in the last trimester. Deformations are defined as anomalies that represent the normal response of a tissue to unusual mechanical forces, in contrast to malformations which arise as the result of a primary problem in the morphogenesis of a tissue. Disruption represents the breakdown of previously normal tissue, as produced, for example, by an amniotic band, and has been implicated in the causation of some types of cleft lip and palate. Deformations have been classified into two types: (1) primary deformations being produced by extrinsic mechanical forces to a normal fetus; and (2) secondary deformations occurring as a result of an intrinsic problem of the fetus, such as a malformed fetus or a malpositioned fetus. Rarely, these can also occur together.

Received for publication 24 July 1984

Revised version accepted for publication 25 January 1985
We report a case of an unusual umbilical cord hernia arising as a secondary deformation in a malformed infant with congenital chondrodysplasia punctata.

\section{Case report}

The male proband, the product of an uncomplicated term pregnancy, was delivered by caesarian section because of cephalopelvic disproportion and clinical evidence of fetal distress to a 25 year old primigravida with blood group $\mathrm{AB}, \mathrm{Rh}$ positive, and VDRL negative. The pregnancy was uneventful except for one episode of maternal urinary tract infection which was successfully treated with ampicillin. An ultrasound at 30 weeks' gestation was normal, and the fetus was said to be compatible in size for the date. The parents are first cousins.

At birth, the baby was deeply cyanotic and in shock and was noted to have multiple congenital anomalies including a large umbilical cord hernia (fig 1). He required immediate resuscitation; Apgar score was 9 at 5 minutes. After stabilisation, the patient was transferred to the Intensive Care Nursery (ICN) at the Jersey City Medical Center. Physical examination in the ICN revealed a term male newborn, weighing $3050 \mathrm{~g}$, length $42 \mathrm{~cm}$, and head circumference $34.5 \mathrm{~cm}$. Multiple anomalies were noted including small skin tags on the lips, short thorax, and widely spaced nipples. Scrotal folds were normal but the testes bilaterally were 


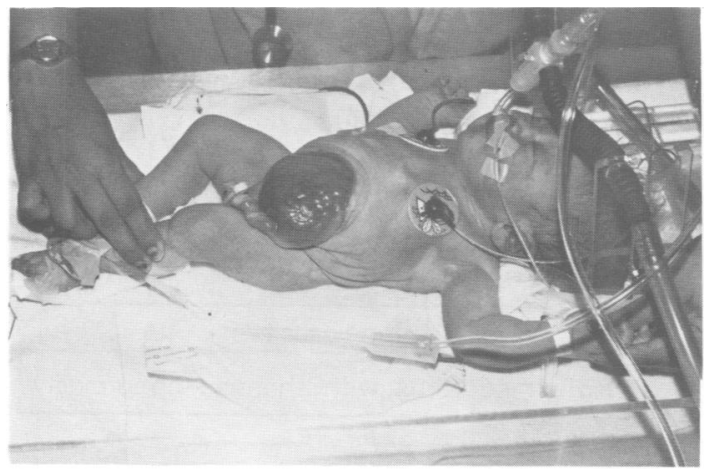

FIG 1 The proband with multiple congenital anomalies: large umbilical hernia and short thorax.

undescended. There was a large umbilical cord hernia measuring $12 \times 12 \mathrm{~cm}$ with intestines and liver visible in the sac. A peripheral cataract was present in the left eye. Bone $x$-rays revealed epiphyseal stippling of the long bones (femora, humeri), abnormal calcification of the sternum, spine, ribs and scapula (fig 2), and periarticular calcification of the left foot (fig 3). After stabilisation, the patient underwent surgical correction of the umbilical cord hernia at 3 hours of age. Postoperatively, the patient went into shock, became cyanotic, and died at 35 hours of age. The mother's perineal area and the

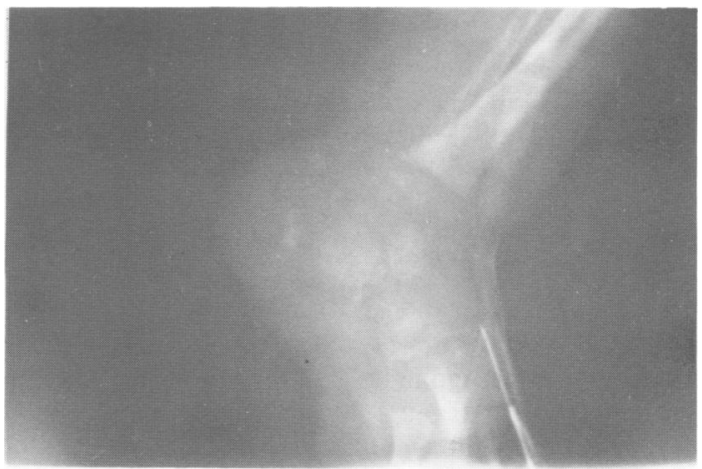

FIG 3 Periarticular calcifications of the left foot.

infant's superficial skin culture grew group B Streptococcus.

\section{Discussion}

Chondrodysplasia punctata is a rare genetic disorder involving the long bones, spine, and pelvis with soft and connective tissue defects with characteristic punctate epiphyseal mineralisation. Microcephaly, mental deficiency, cataracts, and an ichthyosiform skin dysplasia are also associated with this disease. It is invariably lethal.
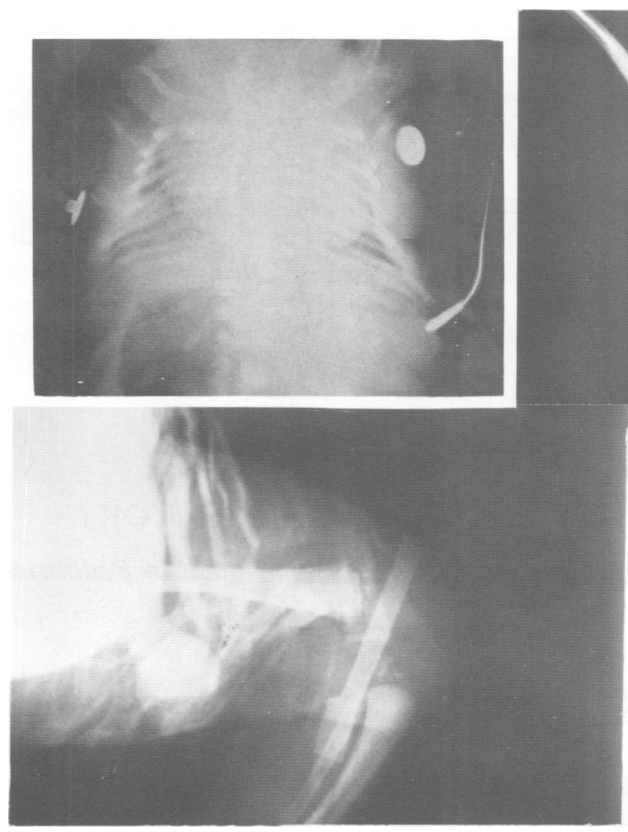
The presence of a large umbilical cord hernia containing intestinal viscera and liver with excessive abdominal skin folds has not been previously noted in this disease. The findings in this case suggest that the umbilical cord hernia arose as a secondary 'deformation' resulting from a combination of extrinsic forces from maternal factors (primigravida uterus and small pelvis) and a malformed fetus (bone dysgenesis and short thorax). The deformative process presumably occurred during the later stages of the pregnancy. The extrinsic forces acted on the malformed fetus and the abdominal contents of the fetus under increased pressure 'herniated' through the area of least resistance, the umbilical cord (fig 4). Adequate abdominal skin folds attest to the fact that there was no primary abdominal wall deformity. As the abdominal contents extruded into the hernial sac the testes were withdrawn from their well formed scrotal sacs (fig 5). It is also possible that the weakening of the connective tissue of the abdominal wall, because of the basic genetic defect, made it easier for the herniation to occur, given the external pressure.

A careful analysis of congenital malformation

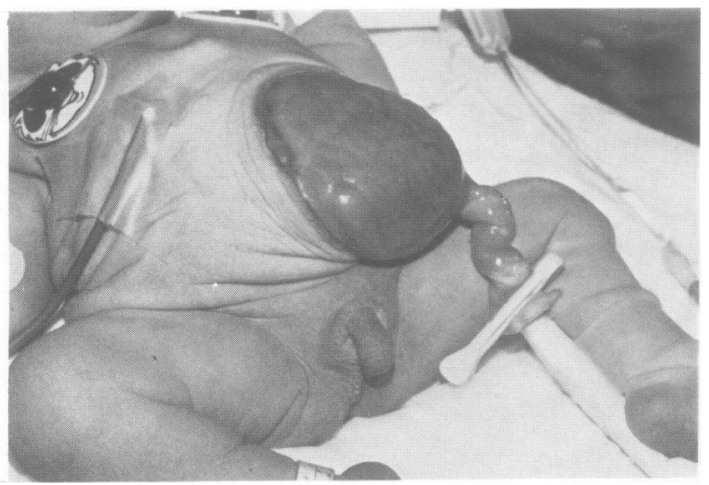

FIG 4 Excessive abdominal skin folds of umbilical hernia and undescended testes with well formed scrotal sac.

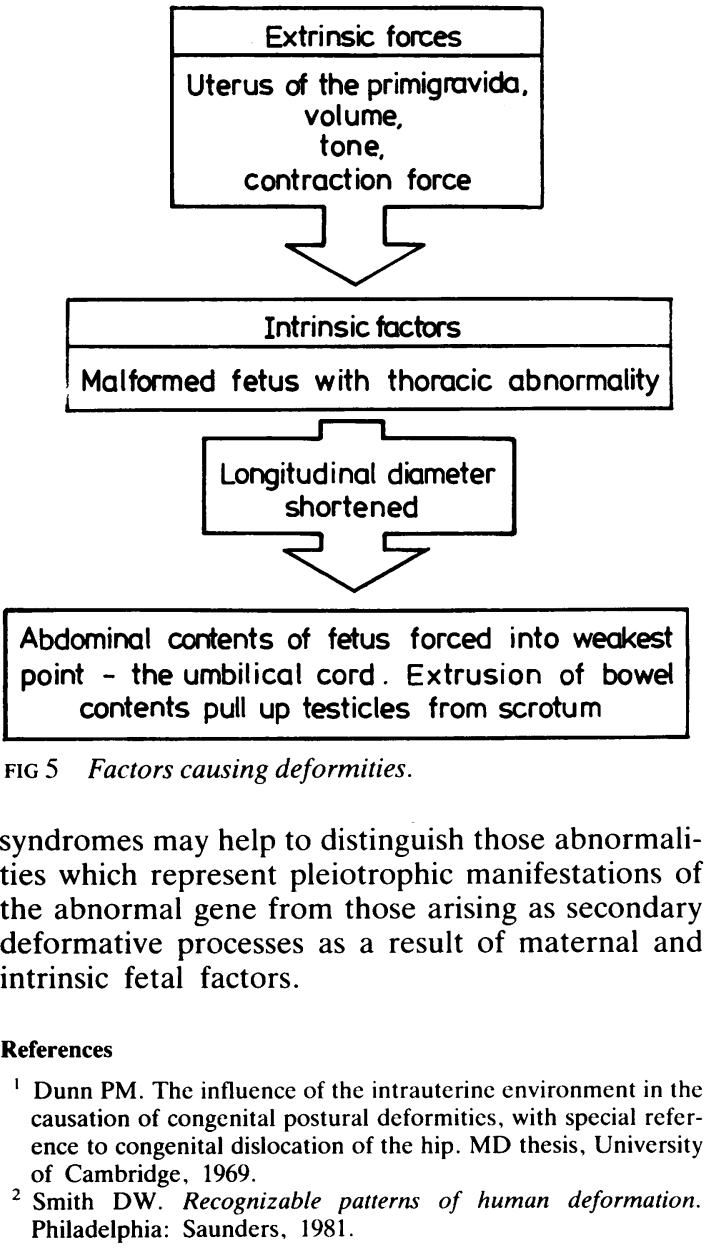

Correspondence and requests for reprints to $\mathrm{Dr} \mathrm{O}$ Chandavasu, Neonatal Services, Jersey City Medical Center, Baldwin Avenue, Jersey City, New Jersey 07304, USA.

\title{
Trisomy 14 mosaicism in a 2 year old girl
}

\author{
MICHAEL B PETERSEN*, LARS O VEJERSLEV*, AND BENTE BECK† \\ *Department of Medical Genetics, The John F Kennedy Institute, Glostrup; and †Department of Pediatrics, \\ Kolding Hospital, Kolding, Denmark.
}

SUMMARY Trisomy 14 mosaicism with 6\% trisomic cells in blood and $16 \%$ in skin fibro-

Received for publication 9 January 1985. Accepted for publication 21 January 1985. blasts was found in a 2 year 2 month old girl with mild psychomotor retardation, craniofacial dysmorphism, pectus carinatum, curved fifth fingers, retarded bone age, and signs of an 